Supplement of Weather Clim. Dynam., 1, 555-575, 2020

https://doi.org/10.5194/wcd-1-555-2020-supplement

Weather and

(C) Author(s) 2020. This work is distributed under

the Creative Commons Attribution 4.0 License.

(c) (1)

Supplement of

\title{
Tropopause-level planetary wave source and its role in two-way troposphere-stratosphere coupling
}

Lina Boljka and Thomas Birner

Correspondence to: Lina Boljka (lina.boljka@colostate.edu)

The copyright of individual parts of the supplement might differ from the CC BY 4.0 License. 


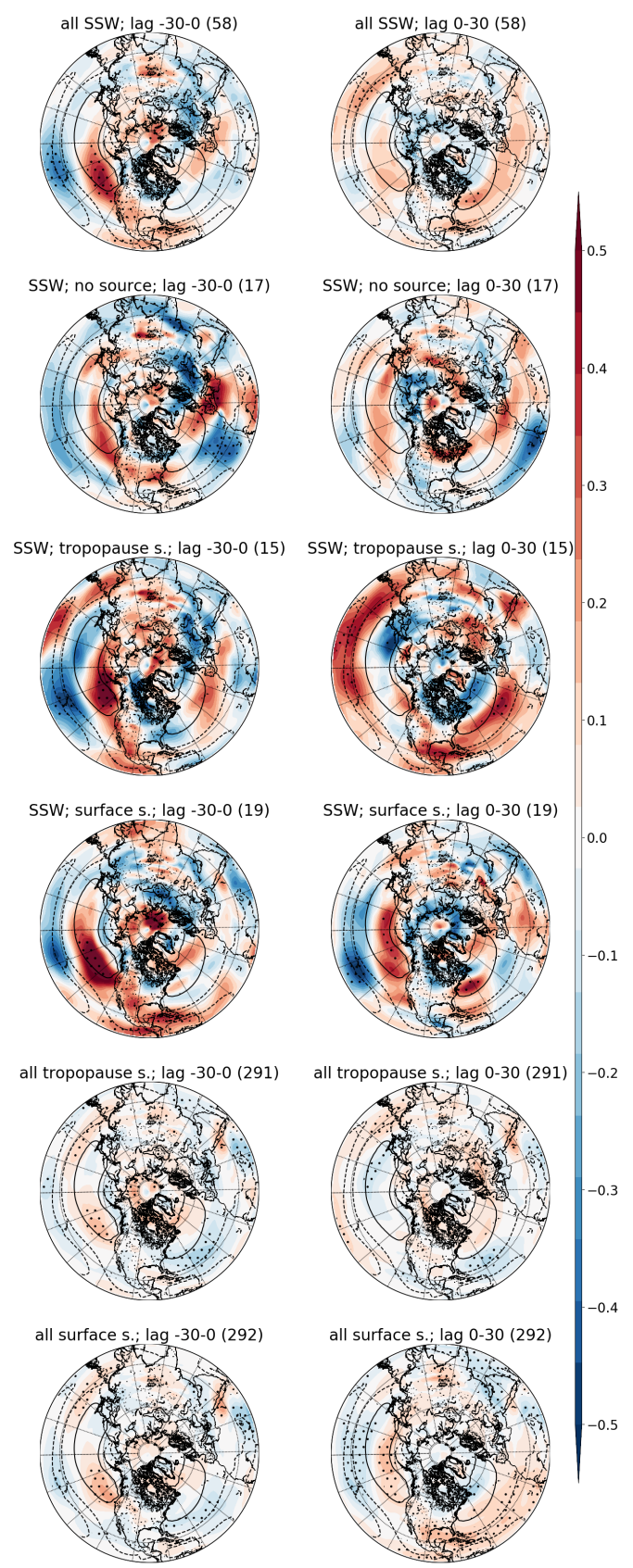

Figure S1. Map-composite analysis of downward impact in zonal wind at $950 \mathrm{hPa}$ (U950) averaged between the lags -30 and 0 days (left column), and 0 and +30 days (right column) around SSW events: (top row) all SSWs, (second row) SSW events not preceded by a wave source, (third row) SSWs preceded by tropopause wave source, (fourth row) SSWs preceded by surface wave source. The bottom two rows show the same but for all wave source events around the central wave source date: (fifth row) all tropopause wave source events, (bottom row) all surface wave source events. The figure shows standardised U950 anomalies (shading) and U950 climatology (contours; contour interval is $4 \mathrm{~m} \mathrm{~s}^{-1}$ with $0^{\text {th }}$ contour omitted for clarity, i.e. ...,-8, $\left.-4,4,8, \ldots\right)$. Stippling denotes values that are significant at $95 \%$ level. Numbers in brackets denote number of events in each composite. Data are from the ERA-20C. 


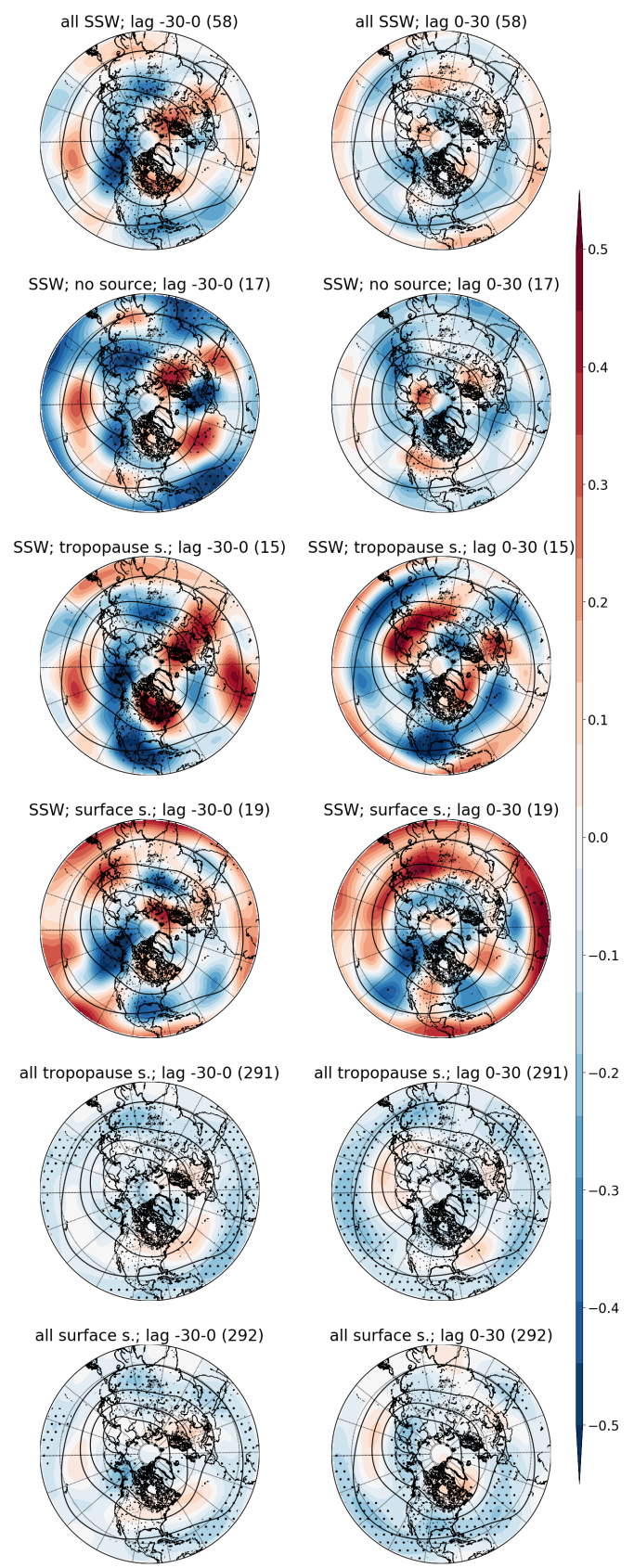

Figure S2. As in Fig. S1, but for geopotential height at $500 \mathrm{hPa}$ (Z500). Here the figure shows standardised Z500 anomalies (shading) and Z500 climatology (contours; contour interval is $200 \mathrm{~m}$, i.e. ...,4800, 5000, 5200,...). 